\title{
O que significa educar para a compreensão da história? Um olhar a partir de um programa de avaliação educacional
}

Sonia Regina Miranda*

\section{RESUMO}

0 artigo visa discutir os significados e importância de um trabalho de "educação histórica" ao longo do ensino fundamental e médio, bem como avaliar algumas tendências verificáveis nesses níveis de escolarização quanto à aprendizagem da História. Para tanto, foram utilizados os resultados auferidos pelo Programa de avaliação educacional empreendido no estado de Minas Gerais.

Palavras-chave: ensino de História, aprendizagem, temporalidade histórica, conhecimento, formação de professores.

Tenho vivenciado, ao longo de aproximadamente 20 anos de profissão, inúmeras situações profissionais que envolvem processos de formação inicial ou continuada de professores nas quais um dilema, aparentemente central, atinge grande número de docentes do ensino fundamental e médio: o que selecionar para ser trabalhado com os alunos como conteúdo histórico essencial e, em contrapartida, o que eliminar? Os alunos devem ou não aprender Período Regencial, Egito Faraônico, Mercantilismo, ou a fase da Assembléia constituinte na revolução Francesa? Precisam ou não estudar Brasil junto com Europa, China, África e Japão? Mas e se o aluno não estudar Unificação de Portugal? Como ele passará pela escola sem eśse conteúdo? Eles podem ou não ficar sem estudar época contemporânea, idade média ou qualquer outro assunto selecionado dentro de uma cultura curricular constituída sobre uma cronologia evolutiva e eurocêntrica? Como resolver, então, o problema do tempo destinado a "cumprir" o programa e, como fazer para tornar tais programas cada vez

\footnotetext{
* Professora de Didática e Prática de Ensino de História no Departamento de Métodos e Técnicas da Educação da Universidade Federal de Juiz de Fora; Doutoranda em Educação pela UNICAMP. smiranda@faced.ufjf.br
} 
mais enxutos sob o ponto de vista das temporalidades que lhes são inerentes? Essas são questões cotidianas que mobilizam os professores, e conforme destaque inicial, projetam-se como essenciais na ação docente, mas obscurecem elementos que se encontram no âmago da discussão e servem aqui para elucidar aquilo que se encontra no eixo central dos problemas que pretendo suscitar neste texto: o que selecionar em História dentre os saberes instituídos e socialmente valorizados? O que está envolvido no chamado pensar historicamente? Que elementos inerentes ao conhecimento histórico devem ser vistos como relevantes sob o ponto de vista da aprendizagem e da formação do indivíduo? 0 que deve constîuir uma ação pedagógica capaz de educar o indivíduo para a aprendizagem da História? 0 que tem caracterizado o saber histórico escolar a partir de um olhar macroscópico sob um sistema escolar público?

Pierre Vilar, ao discutir a especificidade do trabalho histórico, nos alerta para o fato de que o maior perigo da História reside em sua ambiguidade. Ela é uma área de saber que envolve, ao mesmo tempo, "o conhecimento de uma matéria e a matéria desse conhecimento" (VILAR,1985). Isso significa dizer que aquilo que orienta a transposição entre o saber histórico e o saber escolar envolve simultaneamente a narrativa acontecimental e os aspectos inerentes à construção deste mesmo saber. Keith Jenkins leva tal questão à conseqüûências analíticas mais profundas ao destacar que passado e História possuem estatutos ontológicos diferentes e são resultantes de ações e momentos distintos. Uma coisa é o passado em si, entendido genericamente como História, cujo caráter é infinito. Outra coisa é o conhecimento elaborado sobre esse passado, na maioria das vezes, desvinculado do tempo do acontecimento e, portanto, alvo de determinações de inquietações e procedimentos de um outro tempo. (JENKINS, 2001). A dimensão de conhecimento é, portanto, aquilo que se encontra na base constitutiva do que Jörn Rüssen (2001) descreve como sendo a matriz disciplinar da História. Na medida em que o presente sobre o qual se constroem explicações sobre o passado se modifica, modificam-se também os olhares e as perguntas que são projetadas para o passado e, em função disso, a História é continuamente reescrita.

Algumas décadas antes Marc Bloch (1997), em um monumental elogio à profissão do historiador, embora não tenha conseguido concluir a última parte de seu clássico Introdução à História - que, segundo seu plano dedicava- 
se à discussão do ensino da História- deixa claro que dentro daquilo que ele chamou de educação da sensibilidade histórica do indivíduo (BLOCH,1997,101), "o espetáculo da investigação, com seus sucessos e reveses, raramente enfastia. A coisa passada é que provoca frieza e tédio"(BLOCH,1997,118).

De um modo geral, o que se apresenta como hegemônico perante a opinião pública e à mídia em geral em relação ao saber histórico envolve uma concep̧̧ão de História entendida como a matéria desse conhecimento, isto é, a descrição dos eventos do passado. 0 valor pedagógico central advindo dessa perspectiva envolve, claramente, a formação de indivíduos eruditos, informado e inteligentes. No entanto, se considerarmos a análise de Bloch, não é na erudição histórica que reside o caráter formativo da História. Ao contrário disso, a base de uma educação histórica está exatamente nos nexos possíveis que podem ser estabelecidos entre o procedimento histórico e o saber escolar.

Há algumas décadas temos discutido no Brasil o que caracteriza a temática histórica escolar e a validade de um ensino baseado em pressupostos teórico-metodológicos tradicionais e memorizantes. Não temos, no entanto, exclusividade nessa seara de problemas. Em diferentes partes do mundo essa temática acerca da pertinência do saber histórico em dimensões mais específicas tem chamado atenção de pesquisadores e educadores. Ao discutir a natureza do que caracteriza o pensamento histórico e a necessidade de escolarização da criança em relação a temáticas que o desenvolvam, Hilary Cooper, ao pensar a realidade inglesa contemporânea, destacou contundentemente que "às crianças são dadas usualmente perspectivas singulares do passado e não têm sido ajudadas a compreender porque diferentes pessoas, em diferentes tempos, criam diferentes interpretações que podem ser mais ou menos válidas. Os conceitos de tempo e mudança, motivo, causas e conseqüências, similaridades e diferenças têm sido raramente desenvolvidos." (COOPER, 1995). Ao contrário disso, freqüentemente essas mesmas crianças têm sido solicitadas, desde bem pequenas, a explanar descritivamente fatos relevantes, pessoas importantes, temas consagrados por uma historiografia didática de modo acrítico e, sobretudo, aspectos particulares de um passado nem sempre capaz de produzir sentido para sujeitos históricos, que vivenciam o tempo presente. 
A hipótese central que tem permeado minhas investigações é a de que a aquisição da informação histórica se dá, predominantemente, de modo desprovido de qualquer significação para o aluno porque não possui qualquer elo epistemológico ou mesmo cognitivo com o procedimento histórico. É como se o ofício do historiador não possuísse nenhum elo de ligação com aquilo que constitui a disciplina escolar e essa adquirisse sua dimensão formativa exclusivamente por conteúdos constituintes de uma cultura histórica erudita.

0 historiador, em seu trabalho, ainda que possa trilhar diferentes caminhos, persegue algumas diretrizes que identificam o seu trabalho e the conferem identidade própria. Ele seleciona um tema, dentre muitas alternativas possíveis, busca as fontes necessárias e disponíveis para a sua investigação, identifica as formas através das quais aquele tema já foi explicado e que lacunas de conhecimento ainda existem, define procedimentos através dos quais ele irá fazer perguntas aos seus documentos, sistematiza as informações empíricas e, a partir da interação entre as fontes e os seus referenciais teóricos, estabelece explicações a partir das evidências constituídas que podem, na maior parte dos casos, gerar compreensões e olhares muito diversos sobre a realidade. Isso, em linhas gerais, ainda que pese a grande diversidade de alternativas metodológicas e teóricas, é o que caracteriza tendencialmente a profissão do historiador e sua forma de investigar o mundo.

Ao contrário disso, a informação constante nos meios didáticos é recebida, na maior parte dos casos, desprovida desses elos decorrentes do fazer histórico e, nesse sentido, resta aos alunos somente a assimilação e/ou a memorização da informação sobre o passado. 0 efeito negativo principal a ser destacado neste modelo pedagógico é que, por mais sedutor e agradável que seja o conteúdo em tela e, por outro lado, por maior que seja o cuidado do professor com os aspectos cognitivos do aluno em relação ao tema selecionado, há muito pouco de formativo nisso. A erudição continua sendo vista como um objetivo em si mesma e, em geral, o aluno submete-se aquilo que Jorge Larossa comenta sobre a relação entre Agamenon e seu porqueiro: "a verdade é a verdade e devemos acreditar sempre em sua própria condição de verdadeira" (LAROSSA, 2001, 150). Isso implica, em última análise, no distanciamento do aluno e do indivíduo, da compreensão de que existem relações de poder que perspassam 
os enunciados, por mais verdadeiros que possam parecer e que qualquer enunciado, qualquer que seja sua linguagem constitutiva, deve se transformar em objeto de compreensão e desvendamento.

A decorrência central de uma aproximação epistemológica entre a seleção temática do professor e o procedimento histórico reside na particular atenção com a natureza das fontes enquanto objetos de uma produção histórica e, portanto, enquanto enunciados de sujeitos que ocupam diferentes lugares sociais e cuja produção nos remete à compreensão de relações sociais em temporalidades distintas, segundo aquilo que Jacques Le Goff destacou como "documento monumento" (1994). Além disso, tais enunciados também se apresentam para nós enquanto circunstâncias de expressão de diferentes linguagens da realidade e que, por sua vez, pressupõem diferentes processos de educação que permitem a construção de inteligibilidade sobre essas mesmas realidades. Para se compreender, por exemplo, o que tem sido o processo histórico de educação visual é preciso, no trabalho escolar, desconstruir e decodificar as linguagens visuais, desvendando os processos inerentes às linguagens da TV, cinema, fotografia e pintura (ALMEIDA, 1996).

Operando com diferentes fontes e decodificando diferentes linguagens, os historiadores não reconstroem mas reinterpretam o passado à luz de diferentes evidências (THOMPSON,1981), a partir das quais o investigador elabora inferências em função dos quadros explicativos que thes permitam compreender a historicidade de determinadas circunstâncias, e portanto, chegar a um entendimento daquilo que envolve diversidades no tempo. Isso é o que nos leva, em última análise, à possibilidade de pensar historicamente.

Já em 1930 Marc Bloch falava de uma educação da sensibilidade histórica que, antes de vincular-se à assimilação dos conteúdos culturalmente definidos sobre o passado e a evolução da humanidade, deveria basear-se no que a História envolve de pesquisa e, portanto, de escolha, investigação, comparação e, sobretudo um olhar crítico e compreensivo sobre o presente, em consonância com aquilo que a consciência histórica nos dá.

Um trabalho pedagógico que leve o indivíduo a uma EDUCAÇÃO HISTÓRICA, deve ter dois eixos centrais de ação: 
a) em primeiro lugar, deve construir a sensibilidade e a capacidade de apreensão por parte do aluno daquilo que diz respeito ao fazer histórico. Margarida Louro Felgueiras destaca sobre esse aspecto que é nas relações epistemológicas com o desenvolvimento da História enquanto saber e ciência que devem ser buscadas as pontes com o ensino. (FELGUEIRAS, 1994). Sobre esse mesmo aspecto, Hilary Cooper(1995) destaca que a aquisição das habilidades que levam 0 aluno a sustentar opiniões com argumentos, compreender que uma idéia não é "a resposta certa" mas uma dentre possíveis interpretações, e que algumas questões não podem ser respondidas senão a partir de uma investigação que parta das evidências constituem aquilo que pode existir de mais importante para o desenvolvimento cognitivo, social e emocional da criança.

b) Em segundo lugar, um trabalho pela educação histórica deve levar o indivíduo, desde sua infância, à construção da temporalidade. A compreensão tempo, apesar de se projetar como uma das dimensões essenciais vitais e cotidianas do homem comum, envolve um complexo processo tanto de construção cognitiva individual como de assimilação de convenções mutáveis no tempo e resultantes de um grande processo de evolução cultural e modificação histórica (ELIAS, 1998). Nesse sentido, a percepção das categorias temporais envolve, essencialmente, uma construção cognitiva e cultural em longo prazo das noções de causalidade, sucessão, ritmo, duração, simultaneidade, mudança e permanência, bem como a aquisição de um vocabulário específico e mecanismos que permitam a compreensão dos mecanismos utilizados para a medição do tempo.

0 corpus documental sobre o qual buscarei tecer considerações acerca da aprendizagem em História e à construção da temporalidade foi construído a partir dos resultados obtidos pelo Programa de Avaliação da Escola BásicaPROEB, integrante do Sistema Mineiro de Avaliação da Educação Pública. Destes resultados vou analisar alguns aspectos auferidos para a área de História não em sua totalidade, mas em relação às habilidades centrais vinculadas à construção do conhecimento, e à idéia de tempo.

Coordenado pela Faculdade de Educação da Universidade Federal de Juiz de Fora, através do Centro de Políticas Públicas e Avaliação, o PROEB teve o objetivo de, através de um sistema global de avaliação, realizar diagnósticos 
e produzir informações capazes de orientar as políticas públicas estaduais e municipais de educação.

0 trabalho realizado foi uma elaboração coletiva marcada por uma construção teórica aberta que, aos poucos foi constituindo o tom das provas e a categorização dos resultados de modo a dar inteligibilidade a um elenco de indicadores estatísticos que, sem uma base conceitual bem construída, correria o risco de não acrescentar muito sob o ponto de vista da discussão da construção da aprendizagem em História e Geografia. De um total de aproximadamente 1200 questões foram selecionadas 859 que compuseram o pré-teste e, a partir destas, 430 que compuseram o teste. Sob esse ponto de vista a construção do teste foi também uma macro-operação de seleção e, portanto, não teve como meta dar conta de todos os aspectos relacionados ao conteúdo e aprendizagem em História e Geografia. Portanto, ele não teve e nunca terá a pretensão de trazer respostas para tudo mas tendo em vista o caráter teórico metodológico dos instrumentos selecionados temos aqui elementos muito significativos para procedermos a um balanço preliminar a respeito do quadro do ensino de História e Geografia em Minas Gerais, ainda que isso venha como um olhar distante da prática dos atores reais que fazem a escola cotidiana. Estiveram integrados ao programa de avaliação a totalidade dos municípios mineiros que compõem a rede estadual de ensino, bem como alguns municípios com redes municipais, de modo optativo. Isso significou algo em torno de $600 \mathrm{mil}$ alunos avaliados.

A partir dos resultados auferidos com as provas submetidas à totalidade do público investigado foi construída uma escala de proficiência que se apresenta aqui como um modelo global de análise a respeito do processo de construção cognitiva em História e Geografia em relação ao público investigado. Tendo em vista a necessidade de se construir uma informação inteligível ao professor de todos os níveis de ensino, utilizou-se para efeito operacional, a noção genérica de competência cognitiva cunhada por Perrenoud (1999) que envolve 0 desenvolvimento de operações mentais que permitam an indivíduo a mobilização de saberes e sua transposição de situações simples para situações complexas. "Só há competência estabilizada, diria Perrenoud, quando a mobilização dos conhecimentos supera o tatear reflexivo ao alcance de cada um e aciona esquemas constituídos." (PERRENOUD, 1999, P.23). A base de 
transposição dessa noção para aquilo que envolve o ensino de História nos leva à investigação da condição dos saberes discentes envolvidos, por um lado, na capacidade de LER, IDENTIFICAR INFORMAÇÃO, DEFINIR AUTORIA, INFERIR PELA FONTE E COMPARAR e, por outro lado, nas noções que envolvem a construção das noções de temporalidade.

0 modelo de análise proposto para História e Geografia, que foi construído em função do público escolar de Minas Gerais de $4^{a}$. e $8^{a}$. séries do ensino fundamental e $3^{\text {a }}$. série do ensino médio, apresenta 3 campos globais de competências e, a partir desses campos, sub-itens inerentes a habilidades julgadas como fundamentais para o desenvolvimento cognitivo dos alunos em relação à compreensão de seu tempo e seu espaço. Como competências globais foram destacadas as condições de se situar, de estabelecer relações e de generalizar ou comparar. Grosso modo, tais blocos de competências abrigaram questões cujos propósitos inseriam-se, respectivamente, em atributos de observação, análise e síntese, guardadas as devidas proporções para cada série investigada, o que significa dizer que, na prova de quarta série, foram priorizadas questões referentes à observação, enumeração, diferenciação, procedimentos estes entendidos aqui dentro do atributo de análise. Esta proporção manteve-se para a prova de oitava série e só passou a priorizar atributos de síntese na prova de terceira série do ensino médio, embora não se tenha prescindido daquilo que se definiu como base de investigação nas séries anteriores.

As questões do teste, originalmente formuladas em função de uma lista de descritores, foram categorizadas e tiveram os seus resultados avaliados a partir de grandes habilidades e por sua vez, agrupadas nos três blocos de competência genéricos. 0 resultado desse trabalho gerou a construção de tabelas gerais, aqui apresentadas em uma versão modificada nos anexos, que se restringem à demonstração das habilidades envolvidas na construção da idéia de conhecimento histórico (anexo 1) e de temporalidade (anexo 2). Nas tabelas apresentadas, cada linha indica uma habilidade que, pensada dentro de uma competência global correspondente, foi auferida a partir de um conjunto específico de questões vinculadas àquela habilidade em particular.

Nas colunas verticais observamos, na parte de cima da tabela, as faixas de proficiências dentro das quais os alunos de uma determinada escola são posicionados em função de seus resultados. Cada escola recebeu o seu resultado 
particular, apresentando um conceito quantitativo indicador da proficiência média de seus alunos. Essas faixas de proficiência, organizadas em intervalos de $20 \mathrm{em} 20$ pontos, foram construídas em função do processamento dos resultados globais da totalidade dos alunos e da equiparação de tais resultados à escala de análise construída pelo SAEB- Sistema de Avaliação da escola básica, executado sob forma amostral pelo Ministério da Educação. Para fins didáticos, as faixas de proficiência foram agrupadas em 3 conjuntos, expressos por: a) linha contínua (nível crítico); b) quadrados pontilhados (nível intermediário); c) tracejado longo (nível suficiente).

Nas linhas horizontais observamos o modelo geral consituído a partir dos resultados globais e que, portanto, indicam uma tendência global de aquisição cognitiva face ao que foi observado para 0 conjunto da população escolar do estado, sobre o qual foi construída a escala. 0 intervalo branco indica que a competência em questão não começou a ser desenvolvida pelos alunos que se situam na referida faixa. 0 intervalo em cinza claro indica as faixas de proficiência em que a competência em foco encontra-se em vias de constituição. 0 intervalo em cinza escuro indica as faixas de proficiência em que mais de $80 \%$ daquele grupo são capazes de responder positivamente aos itens que avaliam competência em tela e, portanto, indica competências avaliadas como plenamente constituídas.

A leitura da escala em seu conjunto nos mostra, por exemplo, que quem é capaz de, na oitava série, inferir a partir de informações e/ou fontes associadas, é capaz de todo o resto sob o ponto de vista da compreensão do procedimento histórico, isto é, consegue identificar informações em diferentes suportes documentais, compreende a natureza e diversidade de fontes, possui uma compreensão histórica em função de paradigmas não tradicionais e, portanto, associa-a ao estudo dos homens em suas múltiplas dimensões e é capaz de comparar pontos de vista. Por outro lado, verificamos com essa mesma escala que os alunos ao final da terceira série do ensino médio não são capazes de, em geral diferenciar paradigmas historiográficos, o que ainda os coloca longe de uma circunstância de crítica histórica. Além das escalas gráíicas, 0 anexo 3 apresenta uma tabela comparativa na qual são apresentados os resultados globais auferidos no programa sob o ponto de vista do posicionamento da população global, indicando, para tanto, o lugar de cada faixa indicada (críitica, intermediária e suficiente) 
Poderíamos discutir muito a respeito do que tais resultados desvelam ou escondem. Não há dúvidas de que as metodologias que buscam monitorar e investigar o real sob o ponto de vista quantitativo, embora relevantes sob um determinado aspecto, silenciam vozes e atores da complexidade do fazer pedagógico. Michel de Certeau (2001) por exemplo, as renega enquanto alternativas políticas que impedem um olhar sobre diferentes práticas contextualizadas em seus sujeitos. No entanto, ao olhar tais resultados enquanto historiadora que sou, enxergo neles indícios e sinais que me permitem indicar evidências relevantes quanto à situação atual de ausência de uma educação histórica nos termos aqui estabelecidos conceitualmente, ou, dito em outras palavras, do predomínio de uma tendência hegemônica quanto à história ensinada que muito pouco contribui para a compreensão da História enquanto um processo particular de investigar e compreender o mundo.

A partir dos dados indicados no anexo 3 , percebe-se que, na $4^{a}$. série do ensino fundamental ou $1^{\circ}$. ano do ciclo intermediário, a média dos alunos na prova de História concentrou-se na faixa de 200 a 220. A partir da escala isso significa dizer que a maioria dos alunos que se situa nesta faixa de proficiência não tem praticamente nenhuma importante habilidade cognitiva consolidada e é capaz somente de diferenciar dias e anos, compreendendo a duração dessas duas unidades de datação temporal, além de diferenciar produtos e matéria prima.

Os alunos investigados não começaram sequer a desenvolver os seguintes campos de competências:

- fazer operações avançadas de ordenação segundo critérios temporais, 0 que significa dizer que não conseguem, por exemplo, ordenar uma sequiência de indivíduos com a mesma idade que nasceram em meses diferentes do ano, bem como não são capazes de, a partir de uma sequiência de acontecimentos históricos com suas respectivas datas, dizer o que aconteceu antes ou depois;

- diferenciar padrões de vida e comportamento distintos como resultantes de padrões culturais diferentes, sem que necessariamente tenham que ser considerados como errados. Neste caso, a presença de alguns estereótipos é determinante no sentido de se atribuir juízos de valor aos comportamentos e hábitos, sempre avaliados como certos ou errados, atrasados ou evoluídos; 
- diferenciar natureza e cultura, adquirindo, portanto, conceitos chaves para a leitura da realidade e para a compreensão de que o homem produz e transforma a natureza e, esta relação é, em diferentes medidas, objeto de estudo da História e Geografia;

- inserir uma informação dada em um contexto previamente indicado, compreendendo relações entre acontecimentos;

- fazer inferências a partir da compreensão de diferentes temporalidades, entendendo que tudo tem uma origem e se modifica com o tempo e que se um determinado elemento se apresenta como tal no presente ele não é, na verdade, eterno e nem foi desse modo sempre;

- diferenciar situaçóes simpies do passado e presente a partir de suporte iconográfico;

- operar com noções de datação envolvendo a compreensão de séculos.

o fato de ainda não terem iniciado as competências acima assinaladas possui implicações muito significativas na perspectiva de conhecimento que é gerada nos alunos, pois como temos um padrão de cultura curricular que tende a reforçar a antítese erro/acerto, a existência de um grande volume de alunos que não conseguem dissociar diversidade e erro provoca muitas dificuldades para a compreensão das Ciências Humanas como formas de explicação da realidade cujas variações interpretativas referem-se a diferentes lugares sociais e diferentes pontos de vista.

Algumas competências encontram-se, na média verificada entre os alunos, em um movimento de aquisição inicial, sem, no entanto, estarem consolidadas ao final do primeiro ciclo de estudos. Isso significa dizer que há uma tendência geral de os alunos passarem de um ciclo a outro apenas iniciando um procedimento de:

- Identificar informações em suportes classicamente vinculados à apresentação da informação histórica, tais como linhas de tempo, gráficos, tabelas e imagens;

- Compreender a relação entre fontes históricas e diversidade de conhecimento, sendo que, nesse caso é particularmente significativo o fato de que a maior parte dos alunos não seja capaz de associar fontes ou vestígios da cultura material privada à possibilidade de reconstituição da história dos indivíduos, o que está relacionado a uma perspectiva construída 
culturalmente de que a História não estuda os indivíduos mas personagens heróicos e fatos distantes do cidadão comum e este, portanto, não faz parte da História;

- Ordenar informações em uma seqüência de imagens simples e fatos apresentados em narrativas e linhas de tempo simples e, a partir desse suporte, compreender acontecimentos que ocorrem simultaneamente em um determinado recorte temporal;

- Perceber a diversidade econômica, social e produtiva como algo constituinte das sociedades no tempo e no espaço. Na verdade, as questões que serviram para indicar tais situações apresentam, de um modo geral, a diversidade no tempo presente e, em menor escala, em circunstâncias do passado, 0 que torna o problema ainda mais grave se considerarmos a questão do ensino-aprendizagem em História, em que o passado apresenta-se efetivamente como matéria de estudo ao lado do presente;

- Compreender a duração de pequenas unidades temporais, comparando situações simultâneas, bem como representar seqüências e simultaneidades em uma representação gráfica;

- Compreender continuidades e rupturas no tempo, seja sob o ponto de vista dos comportamentos como de hábitos de consumo e formas de vida e trabalho.

Podemos dizer que o conjunto dessas competências estaria teoricamente consolidado em torno da faixa 260-280, o que corresponde a apenas $6,7 \%$ do público total investigado, algo desprezível se considerarmos a concentração da maioria absoluta da população abaixo desse patamar.

Se, por um lado, há um grupo situado em uma faixa considerada satisfatória em termos de proficiência, bem além do nível médio da população, por outro lado foi identificado um outro grupo situado no extremo oposto, até o ponto 200, em um patamar muito distante da média do público investigado e que, portanto, se situa em uma faixa crítica em termos cognitivos. Isso significa dizer que 39,2\% dos alunos terminam a $4^{\text {a }}$. série sem dominar as mínimas condições necessárias a uma compreensão do mundo e, portanto, estão distantes de um patamar mínimo de habilidades que lhes garanta seguir em frente como cidadãos e sujeitos ativos. Sob o ponto de vista das habilidades cognitivas inerentes à aprendizagem em História, isso significa dizer que tais alunos não 
são capazes de processar qualquer tipo de operação que envolva a compreensão da temporalidade; não conseguem compreender o sentido de ordenação e classificação; não percebem diferenças sócio-culturais em qualquer nível ou, pelo menos, não são capazes de enumerá-las; não identificam nem processam informações a partir de diferentes tipos de fontes utilizadas para o trabalho histórico; não fazem inferências ou qualquer tipo de procedimento hipotético, ainda que simples, e não são capazes de comparar circunstâncias históricas diferentes.

Se retomarmos a perspectiva de Paulo Freire sobre a importância do ato de ler, podemos dizer que, em linhas gerais, os resultados obtidos denotam uma tendência geral marcada por uma grande incapacidade de leitura deste mundo e, portanto, projeta um grande número de alunos para um patamar elementar em termos de letramento.

Como năo é possivel pensar o desenvolvimento de habilidades de modo descolado de um conteúdo que lhe seja próprio, a prova de $8^{\text {a }}$. série, mais do que a de $4^{\mathrm{a}}$., teve a maior parte das questões construídas a partir de conteúdos históricos que fazem parte das prescrições curriculares mais comuns, tendo em vista a relação de descritores elaborados para nortear o trabalho da equipe. No entanto, a avaliação das mesmas não foi feita em função de se diagnosticar a quantidade de conteúdos que foi dominada pelos alunos, o que certamente geraria uma escala completamente deturpada em relação aos propósitos gerais do programa. Uma questão construída, por exemplo, sobre um suporte relacionado à Revolução Industrial buscava, dentre outras possibilidades, verificar se os alunos são capazes de extrair uma informação do texto, se conseguem ou não inserir um dado num contexto, se sabem datá-lo ou se identificam a autoria da fonte apresentada. Assim, variadas habilidades foram investigadas a partir de uma vasta gama de temas e suportes. Pela limitação imposta pelo tipo de questão que compõe o teste, isto é, de múltipla escolha, houve um peso maior àquelas relacionadas às habilidades de identificação e relacionamento, em detrimento das questões relacionadas às sínteses generalizantes e à capacidade de argumentação.

$\mathrm{Na} 8^{\mathrm{a}}$. série do ensino fundamental ou no $2^{\circ}$. ano do ciclo avançado , a média dos alunos na prova de História concentrou-se na faixa 220260. A partir da escala isso significa dizer que a maioria dos alunos que se 
situa nesta faixa de proficiência não iniciou o processo de aquisição das seguintes capacidades:

- Ordenação de dados históricos apresentados sobre uma linha do tempo;

- Diferenciação de pontos de vista sobre um acontecimento indicado;

- Realização de inferências e/ou elaboração de hipóteses em circunstâncias em que há informações cruzadas.

Podemos dizer que em relação às três capacidades apresentam-se importantes carências formativas que projetam sérias dificuldades não só para 0 estudo da História como para a explicação da realidade de um modo geral. A questão da ausência de ordenamento apresenta-se como particularmente grave não só pelo seu sentido estruturante em relação àquilo que constitui uma importante base de operação do raciocínio histórico, mas também porque a maior parte dos recursos didáticos disponíveis para o aluno se constitui sobre essa competência, o que significa que o aluno não é sequer capaz de decodificar aquilo que se relaciona ao seu material escolar cotidiano, sobretudo, ao livro didático. Sobre isso nos parece lícito supor que o aluno é permanentemente exposto a uma situação pela qual ele não compreende o significado e não possui instrumentos mentais para utilizá-la enquanto uma ferramenta de leitura.

Nesse nível, foram consolidadas as competências relacionadas apenas às seguintes estratégias:

- Identificação de informações em textos e narrativas de memória;

- Inserção de elementos do cotidiano privado em um contexto histórico definido, percebendo sua historicidade em função de situações simples;

- Diferenciação e reconhecimento de fontes possíveis à reconstituição do passado;

- Identificação de informações em linhas de tempo diretas, o que representa um avanço cognitivo em relação àquilo que se apresentava como uma carência no ciclo anterior.

Tal como na quarta série, permanecem os problemas quanto à identificação de informações em meios clássicos de apresentação de dados de natureza histórica, tais como documentos escritos, gráficos, tabelas e iconografia. A não consolidação desta competência relaciona-se sobretudo à capacidade de leitura das múltiplas linguagens que nos permitem compreender o mundo. Do 
mesmo modo verificam-se problemas vinculados à percepção de historicidade e à capacidade de inferência, apesar dos suportes das questões apresentarem elementos suficientes para que o aluno proceda a tais inferências ou associações e não thes tenha sido solicitada nenhuma informação vinculada à cultura histórica geral.

Podemos dizer que, de um modo geral, os alunos que se situam na média da população iniciam-se no processo de aquisição de algumas competências estruturantes da condição de aprendizagem da História. No entanto, podemos falar em uma tendência geral de promoção dos alunos ao ensino médio apesar de uma tendência de dos mesmos estarem, em geral, incapazes de:

- Processar operações de datação, identificando séculos em diferentes circunstâncias e suportes;

- Extrair informações de diferentes bases documentais de natureza histórica, tais como documentos escritos, gráficos, tabelas e iconografia (fotografia, pintura e charges), inferindo sobre o sentido da autoria e sobre o lugar social de quem fala através da referida fonte;

- Inserir uma informação em um contexto indicado através de suporte documental;

- Ordenar informações obtidas a partir de um texto escrito;

- Elaborar hipóteses consistentes a partir de dados ou provas documentais apresentadas;

- Comparar momentos históricos, compreendendo a existência de continuidades ou rupturas;

- Associar o estudo da História à compreensão da dinâmica da organização social, compreendendo as diferenças entre paradigmas historiográficos tradicionais e renovadores;

- Compreender calendários, bem como as demais formas de datação, como manifestações de cultura e, portanto, variáveis no tempo e no espaço.

Somente os alunos que se situam numa média a partir da faixa 260-280 podem ser considerados como detentores de um nível cognitivo razoavelmente desenvolvido no sentido de ou já terem consolidado ou estarem bastante avançados no processo de construção das competências genéricas associadas à 
condição de aprendizagem da História e de leitura e interpretação do mundo. Isso significa 44\% da população total que participou do exame neste ciclo. Por outro lado, cerca de $13 \%$ dos estudantes submetidos ao teste enquadram-se no extremo oposto, isto é, em uma faixa crítica situada no patamar de até 220 , em que não há início de aquisição de nenhuma das estratégias que fomentam as competências específicas necessárias à aprendizagem em História na medida em que tais alunos não compreendem à natureza da História enquanto forma de conhecimento, seus métodos, procedimentos e suportes.

É importante dizer que tais resultados elucidam uma cultura curricular consolidada e que possui raízes históricas bem definidas. No eixo do currículo real encontra-se uma tradição inventada (HOBSBAWM, 1984) vinculada a uma História tradicional, entendida como um culto aos fatos históricos notáveis, à comemoração de datas cívicas ou festas locais e ao estudo de personagens heróicos.

Apontar tal tendência cultural e histórica é importante neste momento visto que, deste modo, podemos evitar falsas culpabilidades de um corpo docente, em geral, despreparado em relação aos novos paradigmas curriculares e com carências importantes em sua formação inicial, sobretudo no tocante à compreensão de outras possibilidades de abordagem, distintas daquilo que tem sido o seu saber-fazer e sua experiência, centrados na natureza da informação encerrada nos materiais didáticos comumente disponíveis no mercado e na indústria cultural que circundam a escola.

Para a $8^{a}$. série a faixa crítica diminui para menos da metade em relação ao público de quarta série mas é grave o fato de apenas cerca de $7 \%$ dos alunos estarem concluindo esse ciclo escolar dominando efetivamente envolve 0 procedimento histórico básico, isto é, a identificação de informações, leitura de diferentes suportes, comparação de pontos de vista e realização de inferências a partir das evidências apresentadas. Tal ordem de problemas se perpetua até a $3^{\text {a }}$. série do ensino médio, de onde os alunos estão saindo sem serem capazes de, por exemplo, realizar inferências a partir de tabelas e dados quantitativos ou baseando-se em dois ou mais suportes. Tampouco são capazes de identificar paradigmas historiográficos distintos no que tange, por exemplo, à diferenciação de uma história tradicional, factual e heróica, com uma escrita da história não baseada nesses parâmetros e que privilegie outros sujeitos históricos. 
Mantendo-se a coerência em relação aos princípios teóricos que nortearam a construção do teste de História, as questões elaboradas para a $3^{a}$. série do ensino médio buscaram investigar a condição de utilização dos procedimentos que caracterizam o trabalho histórico enquanto mecanismo de leitura e compreensão da realidade. Isso significa dizer que, sob um suporte temático essencialmente ligado à discussão do tempo presente, o teste priorizou questões relativas à observação e à leitura de fontes; comparação de pontos de vista; inferências a partir de suportes próprios ao trabalho do historiador; compreensão de rupturas e continuidades e compreensão das categorias vinculadas à construção da temporalidade, tais como datação, ordenação, duração e simultaneidade. Sob esses aspectos reside o caráter formativo da educação histórica ao longo de 11 anos de escolarização. São habilidades que se, efetivamente constituídas, garantem ao indivíduo uma condição diferenciada de leitura e explicação da realidade e inserção na realidade e no mundo do trabalho de modo ativo e não passivo. Embora abordando as mesmas questões centrais inerentes à capacidade de compreensão da realidade e raciocínio histórico presentes no teste de $4^{a}$. e $8^{a}$. séries, os itens aplicados aos alunos do ensino médio foram marcados por um grau de complexidade sensivelmente maior e priorizando, sempre que possível, procedimentos de síntese que potencializam a capacidade de argumentação.

A aquisição efetiva do conjunto de competências indicadas é algo que ocorre, efetivamente, em torno da faixa 300,0 que corresponde a somente $19,5 \%$ da população total. No outro extremo desse padrão satisfatório, enconțrase um grupo correspondente a $20,4 \%$ do total que não foi capaz de, ao longo de toda a sua escolarização, iniciar a aquisição de nenhuma competência central ao trabalho de educação histórica. A média da população, $60,1 \%$, no entanto, situa-se próxima à faixa 240-300. Nesta faixa de aquisição, nenhuma competência básica inerente ao domínio dos recursos que caracterizam 0 procedimento histórico está dominada, o que significa apontar uma situação particularmente grave tendo em vista o fato de estarmos lidando com o momento final da escolarização. Além disso, não tem sequer início o processo de aquisição das seguintes competências:

- diferenciação de grandes paradigmas historiográficos, o que significa dizer que os alunos não são capazes de reconhecer diferenças genéricas de 
objetos e abordagem entre uma história que valorize eventos heróicos e uma história que preconize o estudo das transformações sociais, do cotidiano de vida, das minorias excluídas, das formas de cultura, das alternativas de resistência, dentre outras possibilidades;

- realização de inferências a partir das evidências disponíveis pelo cruzamento de duas ou mais fontes documentais associadas;

- realização de inferências a partir da leitura e compreensão de dados quantitativos, tais como tabelas com dados estatísticas, gráficos de crescimento econômico e propagandas publicadas em jornais e televisão.

$\mathrm{Na}$ faixa correspondente à alocação da média populacional iniciam-se os procedimentos de aquisição inicial relativos:

- ao processamento de operações de datação, com a compreensão da noção de século;

- à identificação de informações e/ou evidências históricas disponíveis em documentos, gráficos e tabelas, imagens, linhas de tempo, bem como a diferenciação de tipos de fonte e reconhecimento de sua autoria;

- à percepção de historicidade, o que envolve a condição de, por exemplo, não apontar a existência de computadores na Idade Média, bem como compreender elementos, comportamentos e bens de consumo que são próprios do momento atual em que vivemos;

- à percepção de rupturas e continuidades históricas;

- à inserção de informações dadas em um contexto histórico pertinente, fazendo associações entre os acontecimentos;

- ao domínio das categorias elementares vinculadas à compreensão da temporalidade, tais como ordenação (definição de seqüências) e à compreensão dos episódios que ocorrem simultaneamente em uma dada seqüiência que possui a mesma duração;

- à compreensão dos calendários, bem como qualquer forma de datação, como uma construção social, histórica e, portanto, mutável e relativa;

- à elaboração de hipóteses a partir de diferentes tipos de suporte documental, escrito ou iconográfico;

- à comparação de pontos de vista diferentes sobre um mesmo aspecto da realidade.

De um modo geral tais resultados nos levam de volta à perspectiva de estudo da história entendido enquanto uma matéria sobre a qual adquirimos 
um saber universal que invoca uma tradição que deve ser a base da erudição. Isso significa dizer que aquilo que deve constituir a essência de um procedimento de seleção de conteúdos educativos, bem como a definição de aspectos metodológicos para o de trabalho do professor, em termos gerais, ainda encontrase longe dos aspectos epistemológicos e dos procedimentos que caracterizam 0 fazer histórico. Nesse sentido, a História ainda se encontra longe de formar no aluno a condição de pensar o conhecimento e sua geração como algo que se constrói e, portanto, muda segundo os sujeitos e as condições de produção. A formação da consciência histórica como uma habilidade que permite ao indivíduo a condição de compreender o seu próprio tempo (RUSEN, 2001) e a capacidade de pensar historicamente, cedem espaço, nesse caso, à repetição de alguns saberes socialmente legitimados que, na maioria dos casos, não se relacionam à condição do indivíduo compreender o tempo e o espaço, nem tampouco à condição do cidadão adquirir os elementos necessários à compreensão de sua identidade. 


\section{ANEXOS - RESULTADOS DO PROEB/2001- ESCALAS PARCIAIS DE PROFICIÊNCIA EM HISTÓRIA}

Anexo 1 - Sobre os requisitos essenciais para a compreensão da natureza do conhecimento histórico.

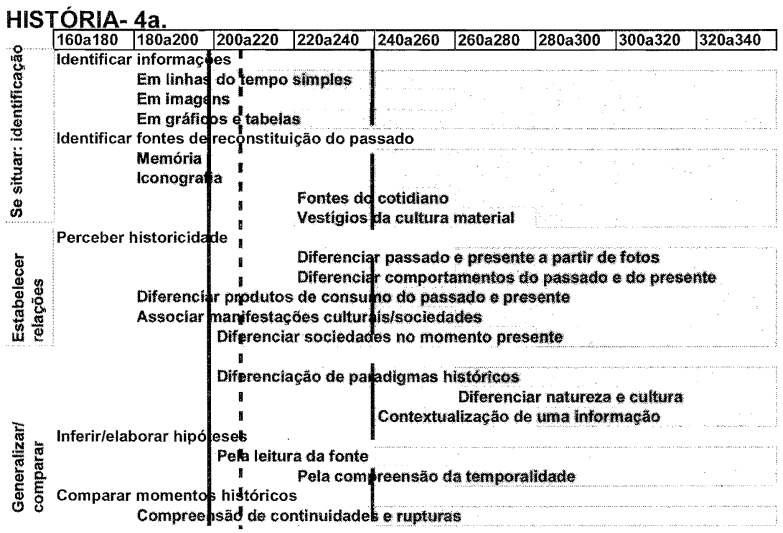

\section{HISTÓRIA- 8 a.}

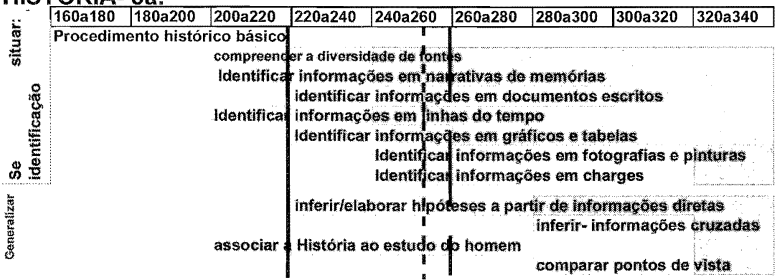

\section{HISTÓRIA- ENSINO}

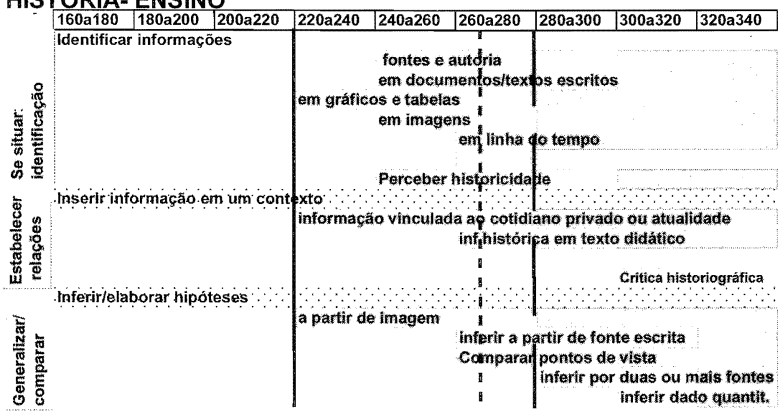


Anexo 2 - Sobre a construção da temporalidade.

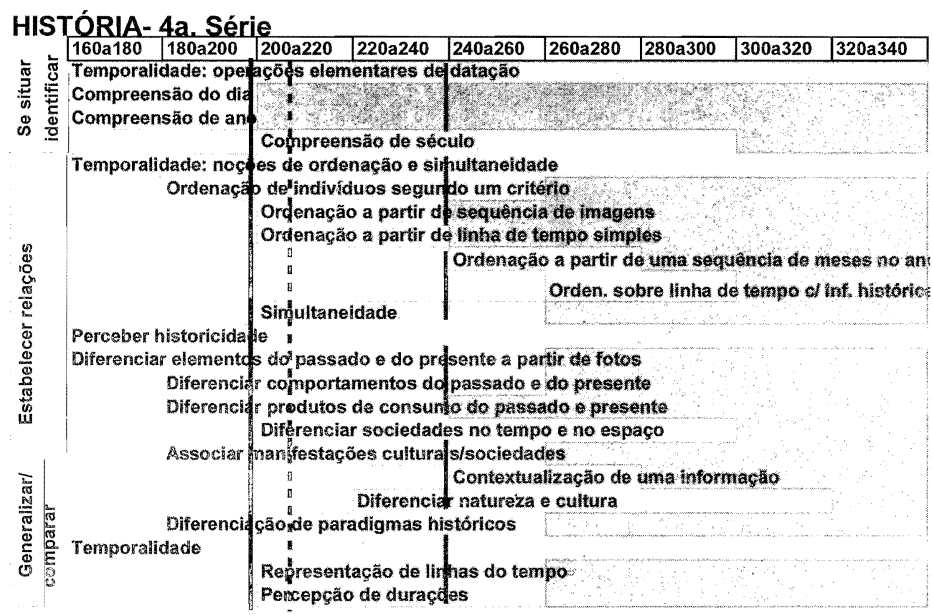

\section{HISTÓRIA- 8a. SÉRIE}
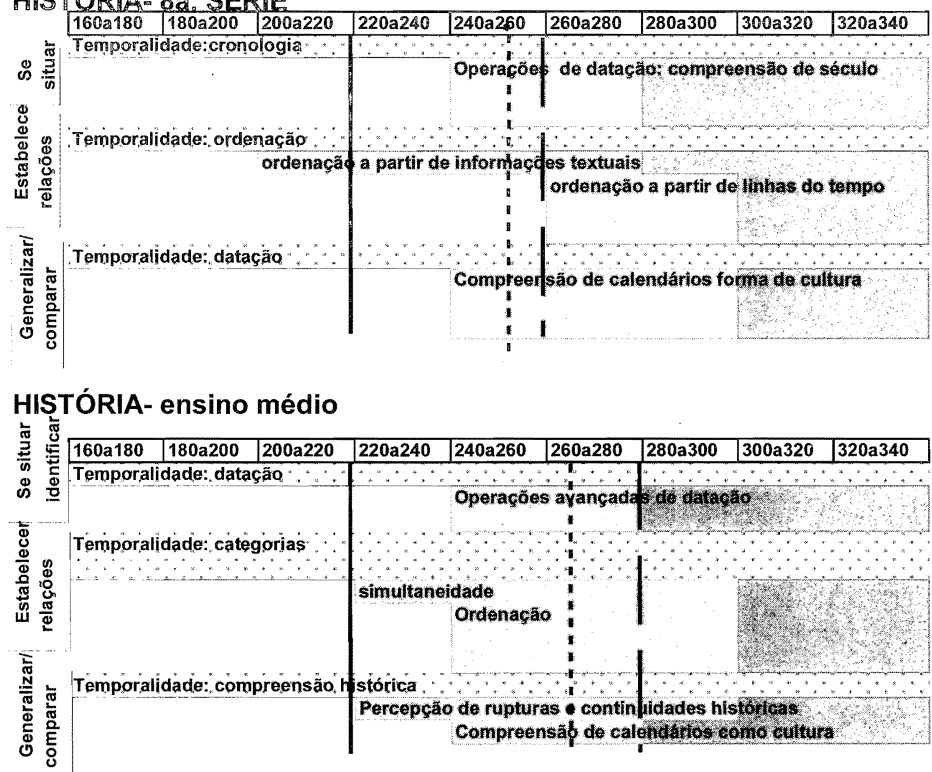
Anexo 3 - Resultados globais SIMAVE - história.

\begin{tabular}{|llll|}
\hline & 4 série & 8 série & 11 série \\
\hline $\begin{array}{l}\text { Ponto médio da população } \\
\text { (mediana) }\end{array}$ & 209,85 & 255,94 & 269,72 \\
\hline Nota mínima obtida & 134.74 & 155.25 & 176.60 \\
\hline Nota máxima obtida & 314.46 & 346.91 & 370.55 \\
\hline Faixa crítica & $39,2 \%$ & $13,3 \%$ & $20,4 \%$ \\
\hline & & & \\
\hline & Sub-faixas até $140 \rightarrow 0,1 \%$ & $160 / 180 \rightarrow 0,4 \%$ & até $200 \rightarrow 1,5 \%$ \\
& $140 / 160 \rightarrow 3,4 \%$ & $180 / 200 \rightarrow 3,4 \%$ & $200 / 220 \rightarrow 6,4 \%$ \\
& $160 / 180 \rightarrow 13,5 \%$ & $200 / 220 \rightarrow 9,5 \%$ & $220 / 240 \rightarrow 12,5 \%$ \\
\hline Faixa intermediária & $180 / 200 \rightarrow 22,2 \%$ & & $60,1 \%$ \\
\hline & $41,2 \%$ & $42,2 \%$ & $240 / 260-17,8 \%$ \\
& & & $260 / 280 \rightarrow 22,2 \%$ \\
& Sub-faixas & $220 / 240 \rightarrow 20,4 \%$ & $280 / 300 \rightarrow 20,1 \%$ \\
\hline & $220 / 240 \rightarrow 22,4 \%$ & $240 / 260 \rightarrow 21,8 \%$ & $19,5 \%$ \\
\hline Faixa suficiente & $19,6 \%$ & & $300 / 320 \rightarrow 12,7 \%$ \\
& & $44,3 \%$ & $>320 \rightarrow 6,8 \%$ \\
\hline & Sub-faixas $240 / 260 \rightarrow 10,6 \%$ & $260 / 280 \rightarrow 23,2 \%$ & \\
\hline & $260 / 280 \rightarrow 6,7 \%$ & $280 / 300 \rightarrow 13,7 \%$ & $300 / 320 \rightarrow 5,8 \%$ \\
\hline & $300 / 320 \rightarrow 0,4 \%$ & $320 / 340 \rightarrow 1,6 \%$ & \\
\hline
\end{tabular}

\section{Bibliografia}

ALMEIDA, Milton. Aproximações em forma escrita sobre as imagens da pintura e do cinema. In: ZAMBONI, Ernesta \& MIGUEL, Antônio. Representações do espaço. Campinas, Autores Associados, 1996.

BITTENCOURT, Circe (org). O saber histórico na sala de aula. São Paulo, Contexto, 1997.

BLOCH, Marc. Introdução à História. Lisboa, Europa-América, 1997.

CARDOSO, Ciro \& VAINFAS, Ronaldo. Os dominios da História. Rio de Janeiro, Campus, 1997

CARDOSO, Ciro Flamarion \& PEREZ BRIGNOLLI, Hector. Os métodos da História. Rio de Janeiro, Graal, 1981.

CERTEAU, Michel de. A cultura no plural. Campinas, Papirus, 2001.

COOPER, Hilary. The teaching of History in primary schools. London, David Fulton, 1995.

ELIAS, Norbert. Sobre o tempo. Rio de Janeiro, Jorge Zahar, 1998. 


\section{ABSTRACT}

The article is aimed at discussing the purposes and importance of a continuous work involving "Historical education" throughout Primary, Secondary and High School, as well as evaluating general tendences present in such school levels concerning History learning. As for this, the results obtained from Minas Gerais Educational Evaluation Programme have been used.

Key-words: History teaching, learning, historical timing, knowledge, teacher training. 